\title{
Frame-shifted proteins of a given gene are unlikely to retain the same function
}

\begin{abstract}
ALEXANDER S. MANKIN
Center for Biomolecular Sciences and Department of Pharmaceutical Sciences, University of Illinois at Chicago, 900 S. Ashland Avenue, Chicago, Illinois 60607, USA
\end{abstract}

\begin{abstract}
In a recently published paper, Huang and coworkers claim that proteins translated in different reading frames from the same mRNA can have similar functions. This conclusion is possibly incorrect due to the possibility that the wild-type protein could still be expressed.
\end{abstract}

Keywords: translation; toxin; frame-shift; ribosome; DHFR

In the recently published paper (Huang et al. 2020), the authors argue that several proteins, including bacterial toxins and one cellular enzyme, retain their activity even when translated from mRNA in $(-1)$ or in $(+1)$ frame (Huang et al. 2020). This is an extraordinary claim that challenges the main principles of genetics and the key concept of molecular biology that the structure of a protein determines its function.

The authors reached their conclusions by deleting one or two nucleotides from the start codons of the studied genes and testing the activity of the resulting products. If the original activity was retained, it was attributed to the protein product being translated in either the $(-1)$ or $(+1)$ frame-a rather exciting assertion. However, in my view, there is a much simpler and less revolutionary explanation for the seemingly paradoxical results presented in the paper.

Let us consider the gene of the membrane-permealizing 19-amino acid long toxin $\mathrm{lbsC}$, which is the main target of the study. The ibsC gene starts with two AUG codons (Fig. 1) of which the first AUG triplet is presumably the authentic start codon (Fig. 1). Even if the first AUG codon is disrupted by deleting one or two nucleotides, it is highly likely that the active toxin would be efficiently expressed in the 0-frame from the second in-frame (!) AUG codon and will simply lack one of the two amino-terminal methionine residues, a mutation which is known to have no effect on the toxin function (Mok et al. 2010). None of the mutations presented in the paper of Huang et al. would

Corresponding author: shura@uic.edu

Article is online at http://www.rnajournal.org/cgi/doi/10.1261/rna. 076398.120. Freely available online through the RNA Open Access option. disrupt the expression of the 0-frame IbsC product. Even when the toxin gene was appended after the gfp-coding sequence, presumably leading to expression of a GFPIbsC fusion, the active toxin could still be individually translated because at least its second AUG codon remained intact in all the fusion constructs.

The same interpretation likely applies to the other "frame-shifted" examples presented in the paper. The claimed (+1) frameshift in the dinQ gene preserves the activity of the encoded toxin not because the alternative frame product is active, but because deletion of $A$ of the AUG codon of the dinQ gene generates a GUG codon (Fig. 1), which is nearly as good a start codon as AUG. Similarly, the 1 or $2 \mathrm{nt}$ deletions within the start codon of the toxin gene tis $B$ preserves the toxin activity not because of the similar activity of the $(+1)$ frame or $(-1)$ frame products, but because in the mutant, translation of the 0-frame product would start at UUG or GUG, both of which are known to be used for translation initiation in E. coli (Gualerzi and Pon 2015; Meydan et al. 2019). Consistently, when mutations made 0 -frame translation impossible (e.g., toxin genes ghoT or pndA), no active product was expressed from the mutant constructs.

In the most striking example presented in the paper, a 78-amino acid enzyme dihydrofolate reductase, DfrB3, from trimethoprim resistant Klebsiella species (Radstrom et al. 1994) is claimed to retain its activity when its gene is translated not only in 0 -frame, but also in $(-1)$ or $(+1)$ frame. However, once again, deletion of A of the AUG start codon would generate an alternative in-frame start codon,

(C) 2020 Mankin This article, published in RNA, is available under a Creative Commons License (Attribution-NonCommercial 4.0 International), as described at http://creativecommons.org/licenses/by-nc/4.0/. 


$\begin{array}{ll}\text { ibsC (0 frame): } & \text { AGGAGAAGGGTT ATG ATG CGA CTT GTC ATC ... } \\ \text { ibsC ('+1 frame'): } & \text { AGGAGAAGGGTT - TG ATG CGA CTT GTC ATC ... } \\ \text { ibsC ('-1 frame'): } & \text { AGGAGAAGGGTT - - G ATG CGA CTT GTC ATC ... } \\ \text { dinQ ( } 0 \text { frame): } & \text { TGGAGAAAACGG ATG ATT GAT AAA GCA ATC... } \\ \text { dinQ ('+1 frame'): } & \text { TGGAGAAAACGG - TG ATT GAT AAA GCA ATC... } \\ \text { tisB (0 frame): } & \text { CAGGAGACGCGT ATG AAC CTG GTG GAT ATC... } \\ \text { tisB ('+1 frame'): } & \text { CAGGAGACGCGT - TG AAC CTG GTG GAT ATC... } \\ \text { tisB ('-1 frame'): } & \text { CAGGAGACGCGT - - G AAC CTG GTG GAT ATC... } \\ \text { dfrB3 (0 frame): } & \text { GAAAGGTCAGAT ATG GAC CAA CAC AAC AAT... } \\ \text { dfrB3 ('+1 frame'): } & \text { GAAAGGTCAGAT - TG GAC CAA CAC AAC AAT... } \\ \text { dfrB3 ('-1 frame'): } & \text { GAAGGTCAGAT - - G GAC CAA CAC AAC AAT... }\end{array}$

FIGURE 1. None of the mutations claimed to lead to the production of the alternative frame products prevent the translation of the 0 -frame protein. The coding sequences are shown in red with the wild-type start codon in bold. The upstream sequences are in black with the putative Shine-Dalgarno sequences shown in bold characters. Nucleotide deletions are shown by dashes. Putative translation start sites in 0 -frame are indicated by arrows.

UUG, and deletion of AU of the start codon would simply restore the 0 -frame AUG codon. Thus, none of the supposedly frameshifting mutations would likely prevent the expression of the 0 -frame product. The authors show that removal of the stop codons found in the $d f r B 3$ in the $(-1)$ and $(+1)$ frames and adding the appropriate start codon not only preserve trimethoprim resistance, but make possible expression and even purification of the frameshifted protein product. These manipulations, however, would not preclude the expression of the 0-frame DfrB3 protein which likely accounts for the observed effects.
In conclusion, because in none of the tested constructs the authentic site of translation initiation was determined, the currently available data presented by Huang et al. can be interpreted in a simple way that does not require the revision of the basic principles of genetics.

\section{ACKNOWLEDGMENTS}

I thank Nora Vàzquez-Laslop, Chetana Baliga, and Kyle Mangano for helpful comments and the anonymous reviewers who brought to my attention some additional points in favor of my interpretation of the data. The work in our laboratory is supported by grants from the National Institutes of Health (R35 GM 127134) and National Science Foundation (MCB 1951405).

Received May 13, 2020; accepted May 30, 2020.

\section{REFERENCES}

Gualerzi CO, Pon CL. 2015. Initiation of mRNA translation in bacteria: structural and dynamic aspects. Cell Mol Life Sci 72: 4341-4367. doi:10.1007/s00018-015-2010-3

Huang $X$, Chen R, Sun M, Peng Y, Pu Q, Yuan Y, Chen G, Dong J, Du F, Cui $X$, et al. 2020. Frame-shifted proteins of a given gene retain the same function. Nucleic Acids Res 48: 4396-4404. doi:10.1093/ nar/gkaa169

Meydan S, Marks J, Klepacki D, Sharma V, Baranov PV, Firth AE, Margus T, Kefi A, Vazquez-Laslop N, Mankin AS. 2019. Retapamulin-assisted ribosome profiling reveals the alternative bacterial proteome. Mol Cell 74: 481-493. doi:10.1016/j.molcel 2019.02.017

Mok WW, Patel NH, Li Y. 2010. Decoding toxicity: deducing the sequence requirements of IbsC, a type I toxin in Escherichia coli. J Biol Chem 285: 41627-41636. doi:10.1074/jbc.M110.149179

Radstrom P, Skold O, Swedberg G, Flensburg J, Roy PH, Sundstrom L. 1994. Transposon Tn5090 of plasmid R751, which carries an integron, is related to $\mathrm{Tn} 7, \mathrm{Mu}$, and the retroelements. J Bacterio/ 176: 3257-3268. doi:10.1128/JB.176.11.3257-3268.1994 

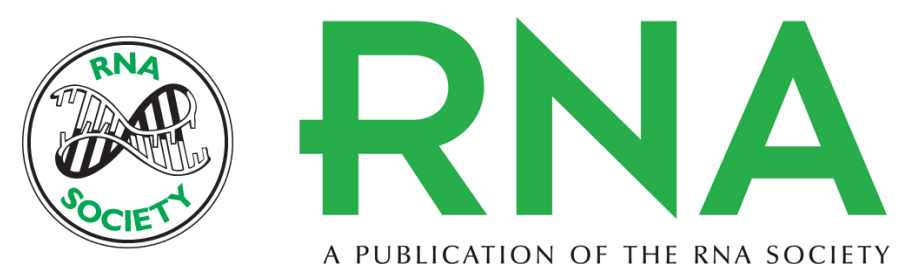

A PUBLICATION OF THE RNA SOCIETY

\title{
Frame-shifted proteins of a given gene are unlikely to retain the same function
}

\author{
Alexander S. Mankin
}

RNA 2020 26: 1301-1302 originally published online June 5, 2020

Access the most recent version at doi:10.1261/rna.076398.120

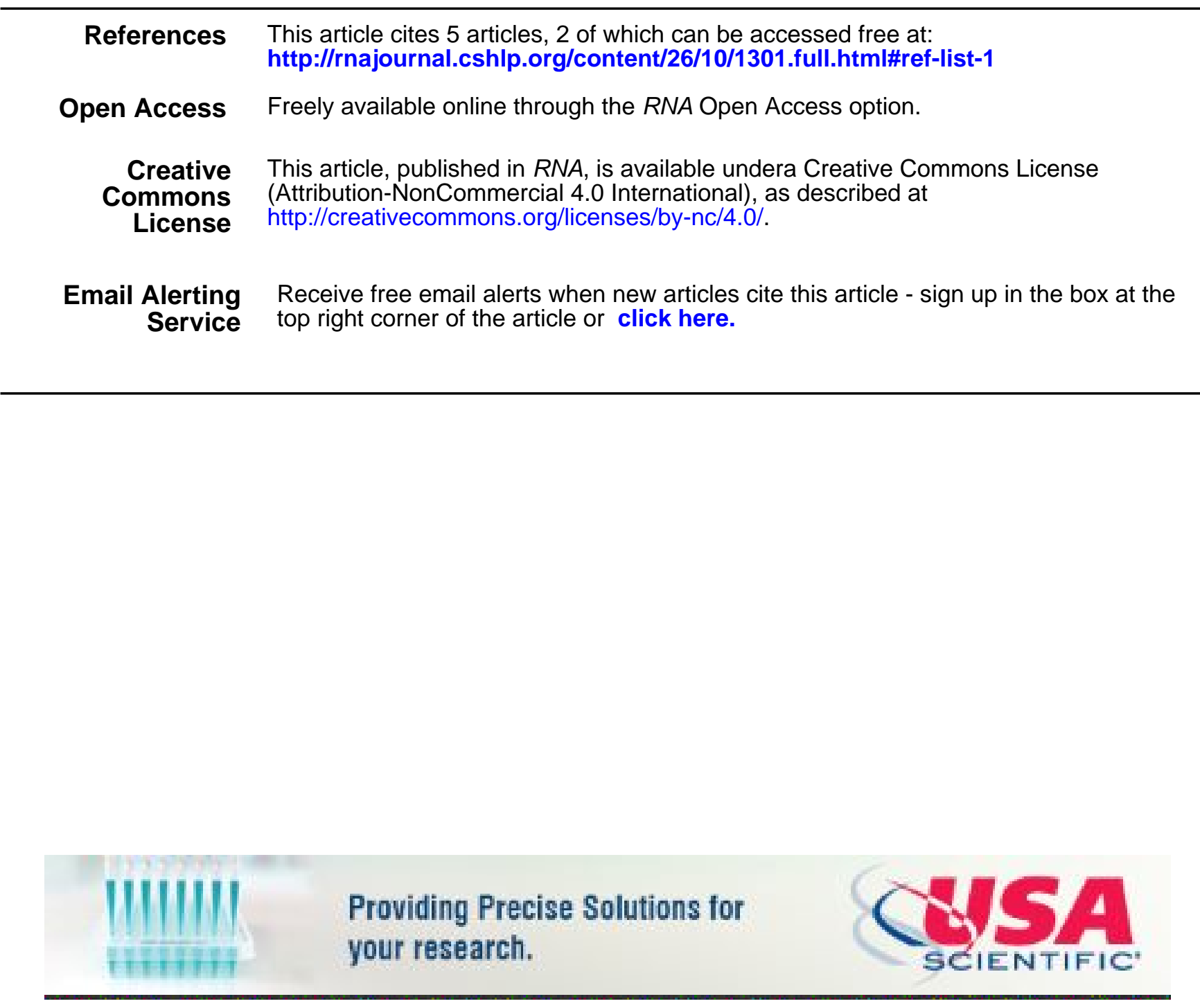

To subscribe to $R N A$ go to:

http://rnajournal.cshlp.org/subscriptions

(C) 2020 Mankin; Published by Cold Spring Harbor Laboratory Press for the RNA Society 